\title{
Closed monitoring of Malaysia COVID-19 using SEIR compartmental model for first wave trajectory
}

\author{
Ramizi Mohamed $^{1 *}$, Zulkifli Mohd Nopiah $^{2}$ and Raja Affendi Raja $\mathrm{Ali}^{3}$ \\ Department of Electrical, Electronic and Systems Engineering, Faculty of Engineering and Built Environment, \\ Universiti Kebangsaan Malaysia, 43600 Bangi, Selangor, Malaysia ${ }^{1}$ \\ Department of Engineering Education, Faculty of Engineering and Built Environment, Universiti Kebangsaan \\ Malaysia, 43600 Bangi, Selangor, Malaysia ${ }^{2}$ \\ Faculty of Medicine, Universiti Kebangsaan Malaysia, 43600, UKM Bangi, Selangor, Malaysia ${ }^{3}$
}

Received: 19-October-2020; Revised: 23-January-2021; Accepted: 26-January-2021

(C)2021 Ramizi Mohamed et al. This is an open access article distributed under the Creative Commons Attribution (CC BY) License, which permits unrestricted use, distribution, and reproduction in any medium, provided the original work is properly cited.

\begin{abstract}
Malaysia COVID-19 trend trajectory has shown significant improvement since Malaysia employed Movement Control Order (MCO) on 18th Mar 2020. Since then a modified compartmental Susceptible, Exposed, Infectious and Removed (SEIR) model has been developed to monitor closely the development on the epidemic. The model introduced early detection factor in order to measure the reliability of the strategy carried out. The closed monitoring is to estimate the current projection of Reproduction Number (RO), a number which a single infected person could outspread the virus to other people, and to forecast in the near future of the number of active cases for several days. This is to show that the strategy carried out by the Malaysian government in order to contain the outbreak whether or not has taken into effect within the period of the first wave of the outbreak. The observation carried out has found out that under the Enhanced MCO (EMCO) or the second MCO showed significant reduction in the number of active cases as well as RO. Not only that the early detection strategy carried out has shown significant improvement of 2.5 to 3.6 times higher than the first MCO.
\end{abstract}

\section{Keywords}

SEIR, Covid-19 trajectory, Transmission rate control parameters, Rapid test factor, Early detection strategy.

\section{Introduction}

China has completed their first wave of COVID-19 epidemic. As of 1st June 2020, the total active cases were 76 with total accumulated cases 83017 all over the China. This number has been almost constant since the city of Wuhan had lifted partially the lockdown on 8th April 2020 by allowing healthy residents and visitors to leave [1-4]. The epidemic patterns showing almost the same projection at the beginning with almost for all countries affected [5]. The same goes to China neighbouring country, South Korea with 810 active cases and 11,503 accumulated cases on the same date [6]. At this current rate South Korea had almost completed the three quarter of the epidemic wave. Other countries (based on the same date) were also showing declining in their active cases, Switzerland, Spain, Italy and Germany but the numbers are still in thousand counts.

*Author for correspondence

135
In terms of deaths, the daily death tolls patterns are still accelerating in most countries, as of 1st Jun 2020 New York showing the highest death tolls so far, with 29,988 in total. The pattern trajectory showing almost similarity even the cause of death has been a subjective matter, which may due to high risk of individuals who were, aged over 60 years and those with underlying conditions such as hypertension, diabetes, cardiovascular disease, chronic respiratory disease and cancer [7, 8]. Other study has shown three possible categories of dying process in COVID19; predominant terminal organ failure, proportionality of care in the dying process and involvement of COVID-19 in the dying process [9].

The recovery pattern (as of 1st Jun 2020) have shown that $89 \%$ of the infected cases were removed from the infected lists and free of virus infection which accounts for $3,286,946$ people. This is believed to be the individuals with mild conditions constitutes to 
$98 \%$ or $3,033,927$ people [10]. The high rate of recovery is in line with several reports that can be found in $[11,12]$. There were also asymptotic cases which may contribute to recovery but the majorities were considered as relatively rare cases from the date of identification or report. However the case due to asymptotic symptoms is still unclear and does not appear to be the major driven of the virus transmission.

The active cases patterns show exponential growth, which later reduce to values range within health care capacity of certain countries. These are the main accountable numbers contributes to SEIR compartmental model, the infected people, the recovered people and the death people, which have been known widely to be the model of any epidemic infectious diseases, particularly in current pandemic COVID-19 [13-18]. Even in tropical country like Malaysia, the SEIR model has been successfully model the dengue outbreak in local states [19-21].

One of the parameter within the SEIR model that contributes the infectivity is known as Reproduction Number, R0. This number represents the possible single infected person to spread the virus, if $\mathrm{R} 0<1$, the outbreak will eventually die. Earlier WHO on Jan 23, estimated the R0 is between 1.4 and 2.5 [22]. Other studies have also estimated that R0 to be between 2.24 and 3.58 [23], which believe the outbreak will follow an exponential growth. Some preliminary studies have also shown that $\mathrm{R} 0$ to be between 1.5 and 3.5 [24-26]. This is in agreement with the projection pattern as stated earlier.

In Southeast Asia, Malaysia is the first country to reach total accumulated cases up to 4000 cases as of 6th Apr 2020 [27]. Although Malaysia showed slow progression of the earlier outbreak, with Singapore lead up to 108 total cases followed by Thailand 43 total cases up to 1st Mar 2020, the sudden growth in Malaysia were presumed to be of several reasons that breaks into several clusters.

This paper presents a closed monitoring of Malaysia COVID-19 cases, based on modified SEIR model with control measures/indicators for first wave outbreak period. The objective of the paper is to demonstrate capability of SEIR model in projecting the number of COVID-19 active cases for several days ahead, at the same time becomes a tool for closed monitoring in estimating COVID-19 projection number. The purpose of the monitoring is to estimate the current $\mathrm{R} 0$ and to project the next $\mathrm{R} 0$ within several days. The estimated $\mathrm{R} 0$ will be an indicator whether or not the strategies taken by the government under the $\mathrm{MCO}$ and the active measure of early detection by the Ministry of Health $(\mathrm{MOH})$ have taken into effect. The strategy of the estimation is to fit the model with non-linear least square technique to the actual data from China, and use the parameter for Malaysian COVID-19 pattern outbreak. This is based on the preliminary assumption that the pattern outbreak from China will be the same throughout any other countries around the world.

\section{COVID-19 first wave Malaysian}

In order to understand the overall scenario of the epidemic, Figure 1 shows the possible timeline clusters of sudden pandemic growth in Malaysia and the enforcement of MCO. In reaction Malaysian government starts to close border on 16th Mar 2020, enacted a 14-days Movement Control Order (MCO) on Mar 18, which has been extended twice to Apr 14 and Apr 28. Under the MCO government and private premises (except essential services), non-essential business, schools, universities and worship places were partly closed, while social and cultural gathering were banned. The police and armed forces were used to control the movement; drones and helicopters were used for monitoring. Those who violated the MCO were penalized and will put under penalty. These were among the measures used to mobilize the enforcement $[28,29]$.

\section{Methodology}

The estimation strategy is by looking at the trend trajectory from China. This is based on the assumption that the same pattern of COVID-19 outbreak originated from China will have the same patterns and implications throughout any other places in the world. Five parameters $(\alpha, \theta, k, \widehat{\sigma}, \hat{\gamma}, \rho)$ need to be estimated by using Levenberg-Marquardt Nonlinear Regression technique for curve fitting and parameter estimation [30-33], which later will be explained in Mathematical Model Description section.

The estimation of the curve projection is based on current infected numbers and daily newly COVID-19 cases. The objective of the projection is to estimate the possible number of active cases and reproduction number $R_{0}$, where $R_{0}$ represents the average number of people to which a single infected person will transmit the virus. We introduced step function, $\beta(t)$, that consist of early transmission rate and control measure parameters to estimate for the next 
projection curve. The step function is needed for future curve projection for any changes based on the current and previous number of active cases at any particular time (dates).
The steps involved in making the projection and estimating the mentioned parameters will be explained in the model description sections.

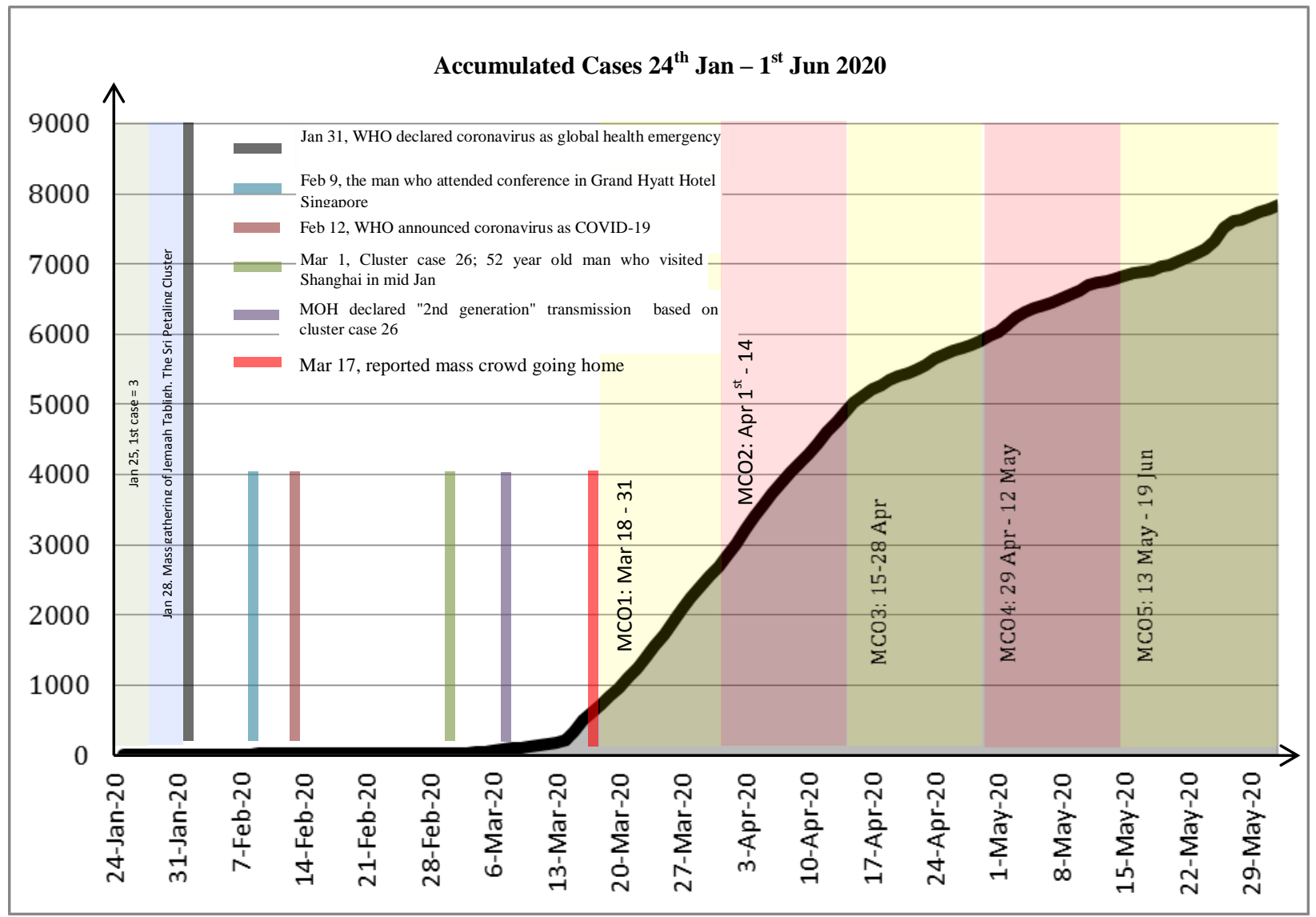

Figure 1 Malaysia COVID-19 brief timeline

(Note: MCO1: 18-31 Mac 2020; MCO2: 1-14 Apr 2020; MCO3: 15-28 Apr 2020; MCO4: 29 Apr-12 May 2020; MCO5: 13 May - 9th June 2020)

\subsection{Model descriptions}

Our model is based on a simple SEIR compartmental model. We adopted the model based on the framework from [34, 35]. Both used control measures to estimate the confirmed infected cases at current time with control transmission rate equation. Two common parameters were introduced to see the effect of the pandemic outbreak of Spanish flu influenza in 1918, later used to see the effect for COVID-19 outbreak in China. The first parameter was earlier introduced by [34] as school-term forcing, later the term changed by [35] to governmental action effect to see the effect of control parameter on the possible COVID-19 projection. The second term was human behavioral response to death. This is to see the response of individuals to the severity cases related to deaths.
We adopted and modified both model to suite the possible solution of current projection, especially by looking at the curve trend projection in China. Equations (1) to (11) show the derivation of the SEIR compartmental model. $\boldsymbol{S}(t)$ represents the susceptible population that can be infected with $N$ total number of population. Our early assumption on susceptible population equals to $0.9 \mathrm{~N}$ an assumptions made by [35]. $\boldsymbol{E}(t)$ is the exposed individuals who goes under quarantine for period of 14 days $[36,37] . I(t)$ is the confirmed cases infected with official report and not considering the individual with onset symptom. $\boldsymbol{R}(t)$ is removed which individual considered as free from virus infection. $\boldsymbol{R}(t)$ can then be further split into individual two recovered $\boldsymbol{R}(t)$ and death $\boldsymbol{D}(t)$. At any time the total number of population equals to $0.9 N=\boldsymbol{S}(t)+\boldsymbol{E}(t)+\boldsymbol{I}(t)+\boldsymbol{R}(t)$. From equation 
(2) the expression $\hat{\sigma} \frac{\sigma}{i_{p}} \boldsymbol{E}(t)$ represents the confirmed cases with $\sigma$ as mean latent period or mean incubation period of 5.1 days $[7,36,38], i_{p}$ represents the maximum incubation period of 14 days and $\hat{\sigma}$ represents the rate of individuals with confirmed detection. Meanwhile the term $\hat{\gamma} \frac{\gamma}{i_{p}} \boldsymbol{I}(t)$ represents the individuals free from the virus with mean infectious period $\gamma$ equals to 5 [35,39], and $\hat{\gamma}$ is the rate of removed.

$\frac{d}{d t} \boldsymbol{S}(t)=-\frac{\beta(t)}{N} \boldsymbol{S}(t) \boldsymbol{I}(t)$

$\frac{d}{d t} \boldsymbol{E}(t)=\frac{\beta(t)}{N} \boldsymbol{S}(t) \boldsymbol{I}(t)-\hat{\sigma} \frac{\sigma}{i_{p}} \boldsymbol{E}(t)$

$\frac{d}{d t} \boldsymbol{I}(t)=\hat{\sigma} \frac{\sigma}{i_{p}} \boldsymbol{E}(t)-\hat{\gamma} \frac{\gamma}{i_{p}} \boldsymbol{I}(t)-\partial \boldsymbol{I}(t)$

$\frac{d}{d t} \boldsymbol{R}(t)=\hat{\gamma} \frac{\gamma}{i_{p}} \boldsymbol{I}(t)+\partial \boldsymbol{I}(t)$

Equation (4) can be further extended into two further equations known as Recovery and Death if one likes to estimate the severity of cases. By rewriting equation (4):

$\frac{d}{d t} \boldsymbol{R}(t)=\hat{\gamma} \frac{\gamma}{i_{p}} \boldsymbol{I}(t)$

$\frac{d}{d t} \boldsymbol{D}(t)=\partial \boldsymbol{I}(t)$

where $\boldsymbol{R}(t)$ represents the individuals, who are no longer infectious and on track to free from the effects of the virus plus the individuals who died from severe cases. $\mathfrak{R}(t)$ represents the recovered individuals and free of infection while $\boldsymbol{D}(t)$ represents the death people at rate $\partial$. The control parameters that incorporated with the SEIR model are shown in the following equations:

$\frac{d}{d t} \boldsymbol{P}_{\boldsymbol{r}}(t)=\rho \hat{\sigma} \frac{\sigma}{i_{p}} \boldsymbol{E}(t)$

$\frac{d}{d t} \boldsymbol{P}(t)=\rho \hat{\sigma} \frac{\sigma}{i_{p}} \boldsymbol{E}(t)-\frac{\lambda}{\lambda_{\max }} \boldsymbol{P}(t)$

Where $\boldsymbol{P}_{\boldsymbol{r}}(t)$ represents the function of quickness in early detection starting from the onset symptom to actual reported cases that control by the parameter $\rho$. $\boldsymbol{P}(t)$ represents the public positive response and reaction to the government order on movement control with $\lambda$ as mean public reaction to MCO fixed at 11.2 days. Whereas $\lambda_{\max }$ represents maximum public reaction fixed at 21 days [34].

The cumulative number of cases can be obtained from:

$\frac{d}{d t} \boldsymbol{A}(t)=\hat{\sigma} \frac{\sigma}{i_{p}} \boldsymbol{E}(t)$

By neglecting the number of recovery and deaths the cumulative reproduction number can be computed as:

$\boldsymbol{R}_{\mathbf{0}}=\frac{C \Delta \boldsymbol{I}(t)+C \Delta \boldsymbol{R}(t)}{C \Delta \boldsymbol{R}(t)}$

However, the time variant reproduction number can be obtained numerically inside the SEIR model by using equation (3) and (4) as shown by [13, 40, 41]. We used control parameters to see the variance of the curve projection as discussed previously with few modifications. Equation (12) shows the transmission rate with control parameters:

$\beta(t)=\beta_{0} \cdot(1-\alpha) \cdot e^{-\theta \cdot \boldsymbol{P}_{r}(t)} \cdot\left(1-\frac{\boldsymbol{P}(t)}{N}\right)^{k \cdot k_{\max }}$

Where $\beta(t)$ represents the time domain transmission rate with basic transmission $\beta_{0}$ equals to 1.68 . This is also based on assumption of initial $R_{0}$ equals to 2.8 $[23,26,35,42]$ with an assumption that $R_{0}=\frac{\beta_{0}}{\gamma}$. $\frac{\sigma}{\sigma+\mu}[35,41] . \alpha$ represents the enforcement of government under the movement control order earlier known as $H(t)$ school term forcing equals to -1 when schools closed [34]. $\boldsymbol{P}(t)$ represents the public positive reaction and response function with strength $k$. We used normalized value of $k$ later used for fitting purposes by multiplying it with constant $k_{\max } \rightarrow \infty$. The modification of $\boldsymbol{P}(t)$ was made based on the number of active cases rather than number of severe cases of death. $\boldsymbol{P}_{r}(t)$ is the function to represent the early virus detection strategy that incorporate with the current number of confirmed infected individuals (equation 7) with $\theta$ as the parameter control. The effect of early detection can be seen with the following ratio:

$\xi_{r}=\frac{1}{\theta}$

The early test indicator of equation (13) can be seen with the sudden increase of infected number, higher number of $\xi_{r}$ means more individuals will have earlier detection. The modified SEIR model developed is based on the assumptions that there are no zoonotic cases and no emigration rate. 
The system configuration is based on the SEIR model of the Equations (1) to (4), known as compartment model. It starts from compartment $\frac{d}{d t} \boldsymbol{S}(t), \frac{d}{d t} \boldsymbol{E}(t)$, $\frac{d}{d t} \boldsymbol{I}(t)$, and ends with compartment $\frac{d}{d t} \boldsymbol{R}(t)$. The estimation process works along the equations by calculating all parameters numerically, as set in Equations (7) to (12).

\section{Results and discussion}

We present the results in two sections, the effect of control parameters and the closed monitoring of R0 for Malaysia COVID-19. The dataset were obtained from worldometer for accumulated cases, active current cases, daily new cases, incremental numbers, number of recovery and number of deaths. The active current cases are used to estimate the reproduction number, R0, as well as the removed (number of deaths plus number of recovery) for modelling. The estimation is set until the end of May 2020 for Malaysia first wave COVID-19.

\subsection{The effect of control parameters}

The effect of control parameters can be seen from the two earlier work $[34,35]$ but with few modifications. Here we only present the effect of early detection strategy. The equation (12) incorporates with three parameters to see the magnitude variations; we maintained the effect of governmental strategy on MCO as $\alpha$ and the effect of public response as normalized $\mathrm{k}$. The effect of early detection strategy $\theta$ is motivated by reported cases from China on $12 \mathrm{Feb}$ 2020 where newly reported cases suddenly rose to 14108 individuals in a single day [1]. The report can be found on several news [43-45].

Figure 2 shows the fitting results before and after the rapid test techniques employed by the China government. It was found out that the rapid test carried out by the Chinese government manage to detect almost twenty times faster than the normal lab test. Table 1 tabulated the parameters for the two periods.

Figure 3 shows the effect of early detection test strategy for China overall fitting results from 22 Jan 2020 until 1st April 2020. By increasing the $\xi \mathrm{r}$ by factor 0.2 it shows that an increasing number of positive COVID-19 (to show early detection) due to active action from the government to control the outbreak. On the other hand, by increasing $\xi \mathrm{r}$ the outbreak could end almost at the same time and the numbers of active cases were very close for each projection towards the end. The basic fitting result parameters are shown in Table 1, which later use for probable projection for Malaysia COVID-19.

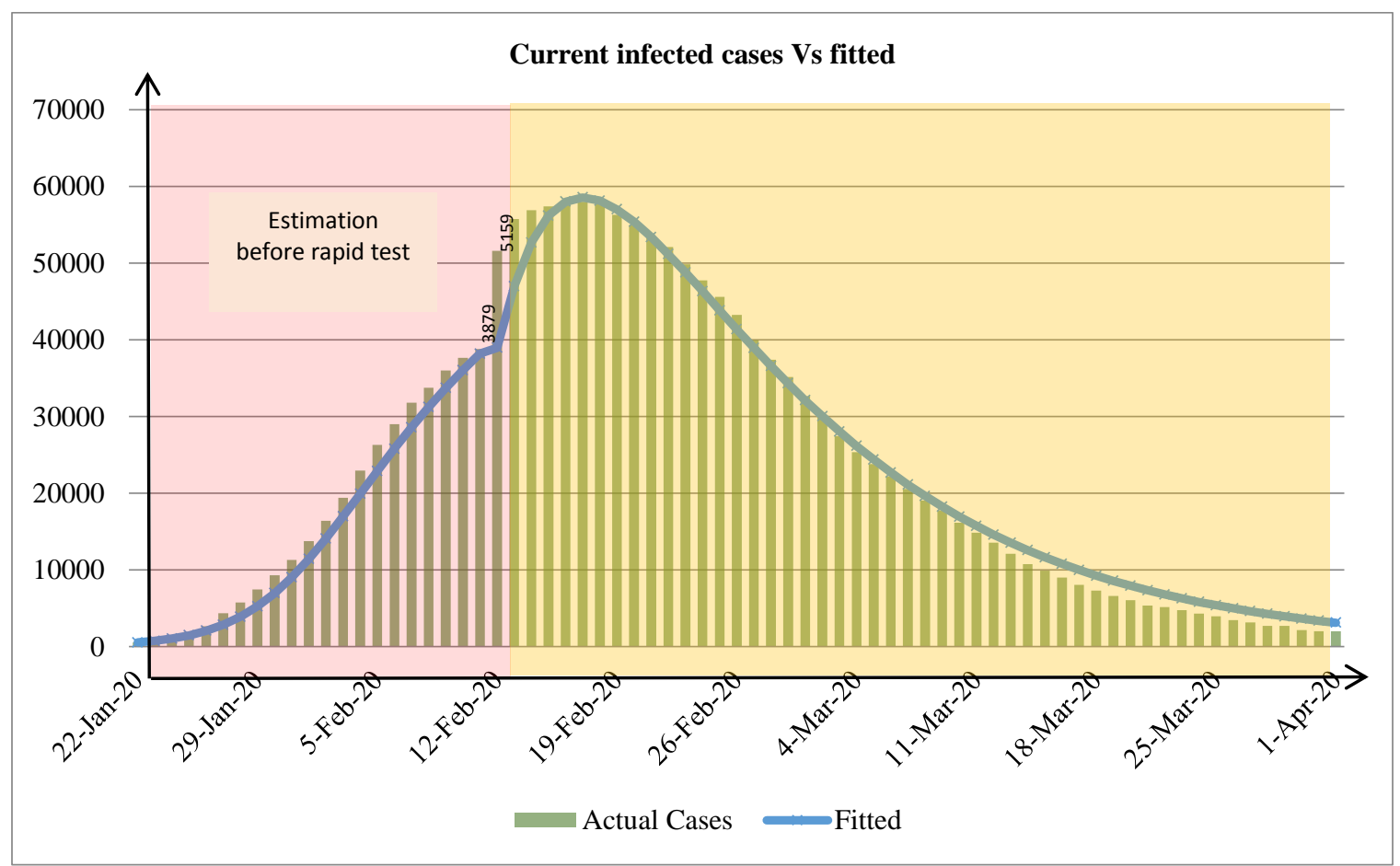

Figure 2 Current infected cases for China vs estimated curve using Lavenberg-Marquadt regression techniques with rapid test parameter (Data fitted until $1^{\text {st }}$ Apr 2020). 


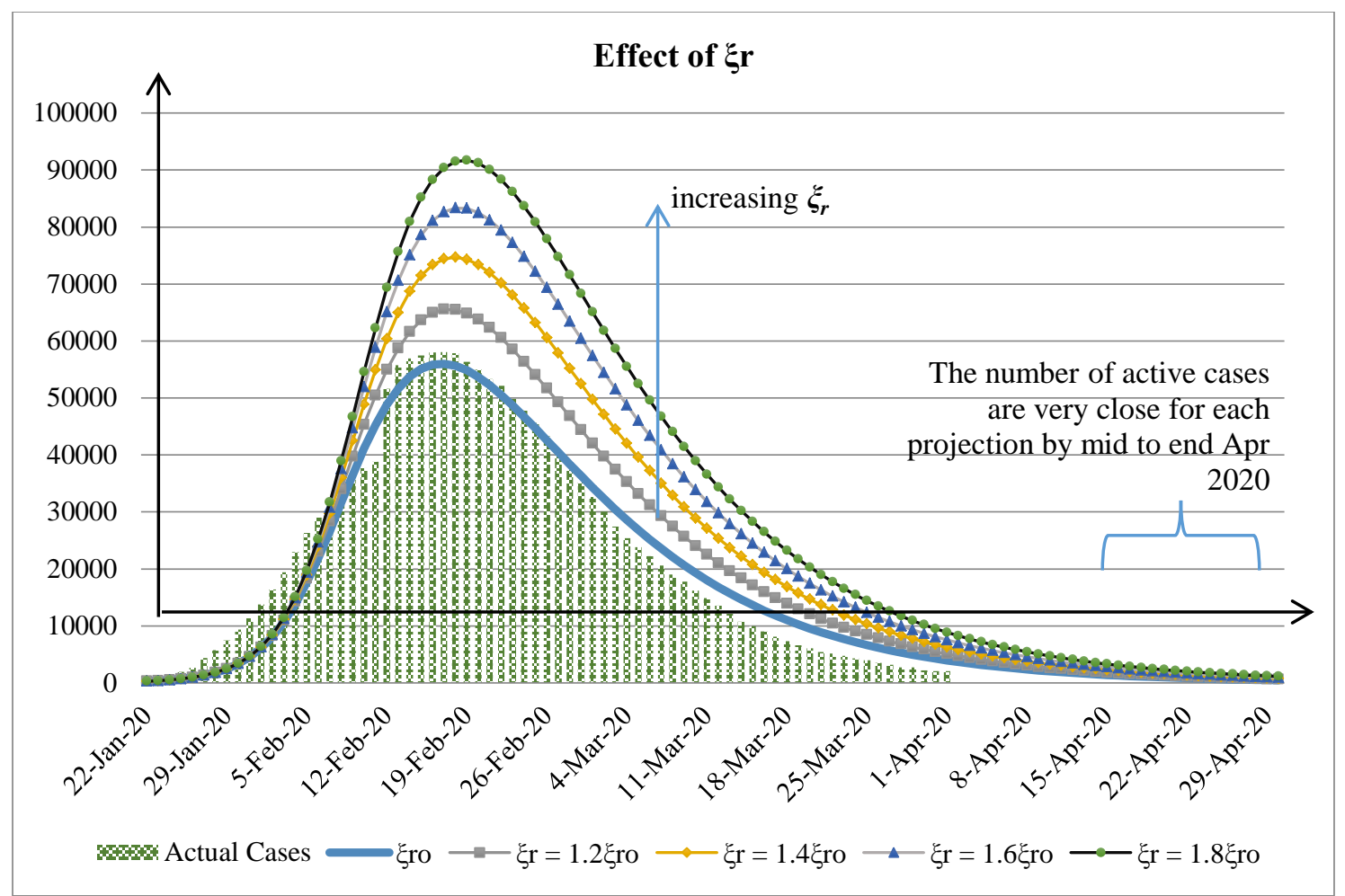

Figure 3 The effect early test indicator $\xi_{\mathbf{r}}$ (Data fitted until $1^{\text {st }}$ Apr 2020 for China).

Table 1 SEIR fitting parameters before and after rapid test by China

\begin{tabular}{lccccccc}
\hline Parameters & $\boldsymbol{\alpha}$ & $\boldsymbol{\rho}$ & $\boldsymbol{k}$ & $\hat{\boldsymbol{\sigma}}$ & $\hat{\boldsymbol{\gamma}}$ & $\boldsymbol{\theta}$ & \multicolumn{3}{c}{$\boldsymbol{\xi}_{\boldsymbol{r}}$} \\
\hline Before rapid test & 0.01064 & 0.00018 & 0.12968 & 0.49450 & 0.02807 & 0.39161 & 2.6 \\
\hline After rapid test & 0.16828 & 0.00137 & 0.00100 & 4.20643 & 0.28621 & 0.01992 & 50.2 \\
\hline $\begin{array}{l}\text { Overall Fitting } \\
\text { test result }\end{array}$ & 0.01000 & $* 0.00279$ & 0.00100 & $* 0.48555$ & $* 0.24486$ & 0.01244 & $\begin{array}{l}\boldsymbol{\xi}_{\boldsymbol{r 0}} \approx \\
80.4\end{array}$
\end{tabular}

*note: These parameter values will be used later for probable projection for Malaysia COVID-19 (later known as SEIR parameters)

\subsection{The results on first wave trend trajectory for} Malaysia

Based on the fitting results obtained in Table 1, the fitting parameters will be used for the next projection results. We used Levenberg-Marquardt Nonlinear Regression technique to estimate the current projection to estimate the current value of control parameters $\alpha, \theta$ and $k$. By combining the fitted SEIR parameters and current fitting parameters from Malaysia active current cases and daily new cases the new projection would be possible. The possible new projection is made by estimating the current value of $R_{0}$ from curve fitting since beginning to current date and multiplies by the factor $\xi_{r}$. This is based on the assumption that no changes or intervention at current time. Hence the projection factor $(\mathrm{PF})$ is given by:

$$
\left.\begin{array}{c}
\text { Projection Factor }(P F)=\xi_{r} \cdot R_{0} \\
\theta=\frac{1}{P F}
\end{array}\right\}
$$

and fed into Equation (12).

The first full projection was made on 22nd Mar 2020 as shown in Figure 4. New $\beta(t)$ is introduced for overall possible projection at $22^{\text {nd }}$ Mar 2020 with estimated $R_{0} \approx 2.23$. The peak number of active cases was expected to be around 3600 people on 5th Apr 2020. The expected $R_{0}<1$ is estimated to be in the early April to mid-April 2020, which in agreement to Malaysian government MCO1 and $\mathrm{MCO} 2$ end dates. In actual case, the peak number of active cases was 2596 people on 5th Apr 2020. 
The second projection $\beta(t)$ was introduced on $26^{\text {th }}$ Mar 2020 with an estimated $R_{0}$ equals 2.37, which shows no declining projection since $22^{\text {nd }}$ Mar 2020, until expected to go down by 6th Apr 2020 as shown in Figure 5. The rapid increase was believing to be the cause of the Tabligh Sri Petaling cluster [46]. However, on $6^{\text {th }}$ Apr 2020, under the second MCO, the margin begins to expand and the number falls far below the estimation with the margin of 205 as shown in Figure 5.

Hence Figure 6 shows new projection made on $5^{\text {th }}$ Apr 2020 to see the new pattern projection until the end of MCO2. It was estimated that by $5^{\text {th }}$ Apr 2020, the estimated $R_{0}$ to be 1.12. Until $9^{\text {th }}$ Apr 2020, the actual projection was still remained intact. The number of active cases follows closely to the estimated projection. At this current rate the estimated $R_{0}$ was 1.03 , and expected to reach below 1 by $14^{\text {th }}$ Apr 2020 with $R_{0} \approx 0.92$. The analysis can be seen in Figure 6.

Under the second MCO the government has enforced an Enhanced MCO (EMCO). This includes active test by the $\mathrm{MOH}$ in order to have earlier detection, earlier isolation and earlier treatment. Starting 27th Mar 2020, with EMCO specific locations were subjected to a stricter order for 14 days, if a large cluster was detected within the area in order for the government to conduct a thorough COVID-19 test towards all residents. Among the orders are all residents or visitors are forbidden to exit or entering the area, all business are closed, adequate food supplies will be given by authorities, medical base will be established within the area and all roads are blocked [47].

As a result on $15^{\text {th }}$ Apr 2020, new assessment were made to see the actual progress and found out that the Malaysian government were doing very well under the second MCO. This is clearly seen from Figure 7. The pattern shows that since $5^{\text {th }}$ Apr 2020 a significant reduction on the number of active cases were far below the estimated projection with margin of 204 people by $14^{\text {th }}$ Apr 2020, and $R_{0} \approx 0.84$, far from earlier projected curve. This shows a good sign that the strategy begin to take place under the second MCO. In order to see the estimated $R_{0}$, a new projection was made on $14^{\text {th }}$ Apr 2020 to forecast for the next projection and expected to have around 1997 active cases by $21^{\text {st }}$ Apr 2020 with $R_{0} \approx 0.6$.

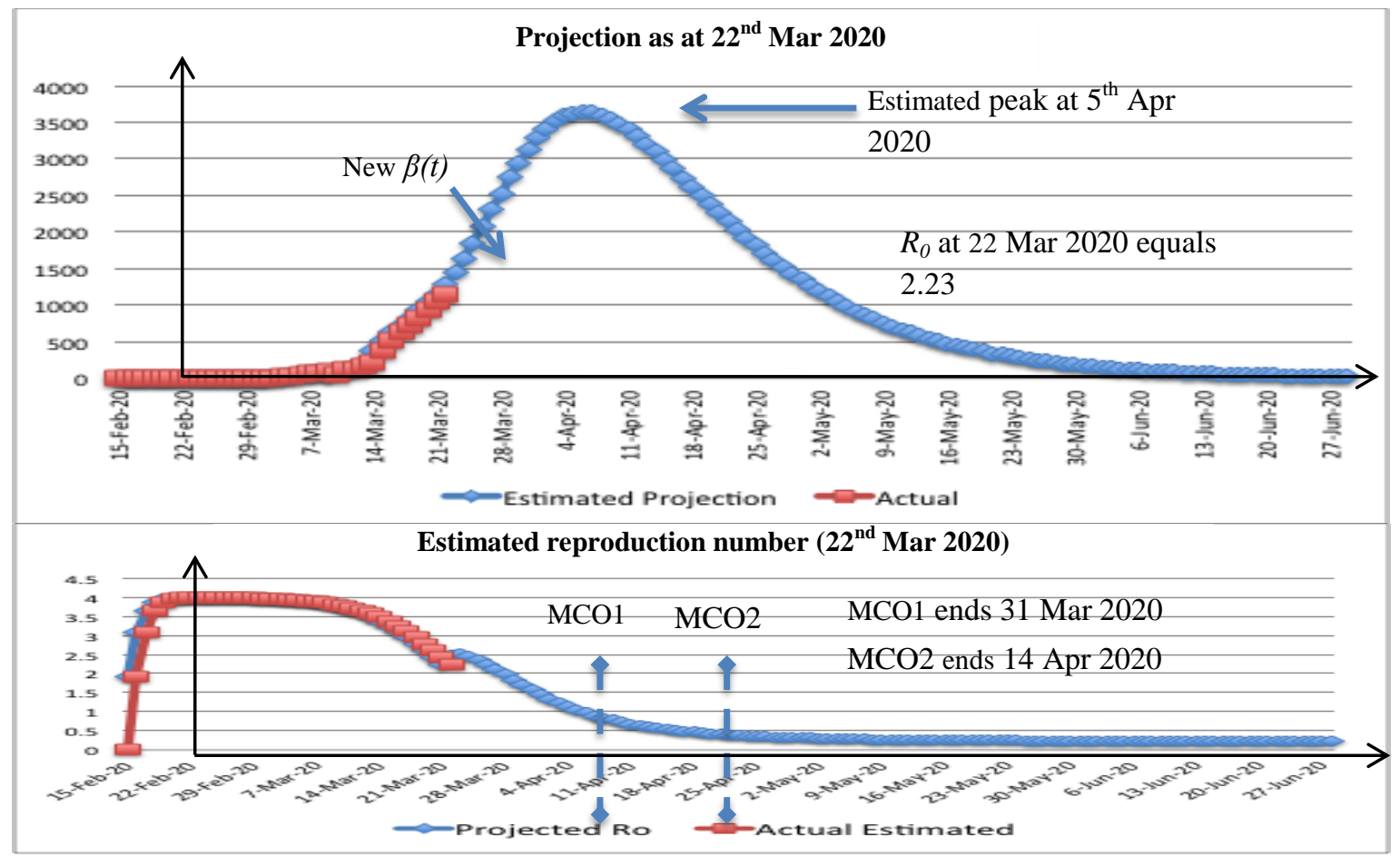

Figure 4 First full projection on 22nd Mar 2020 
Ramizi Mohamed et al.

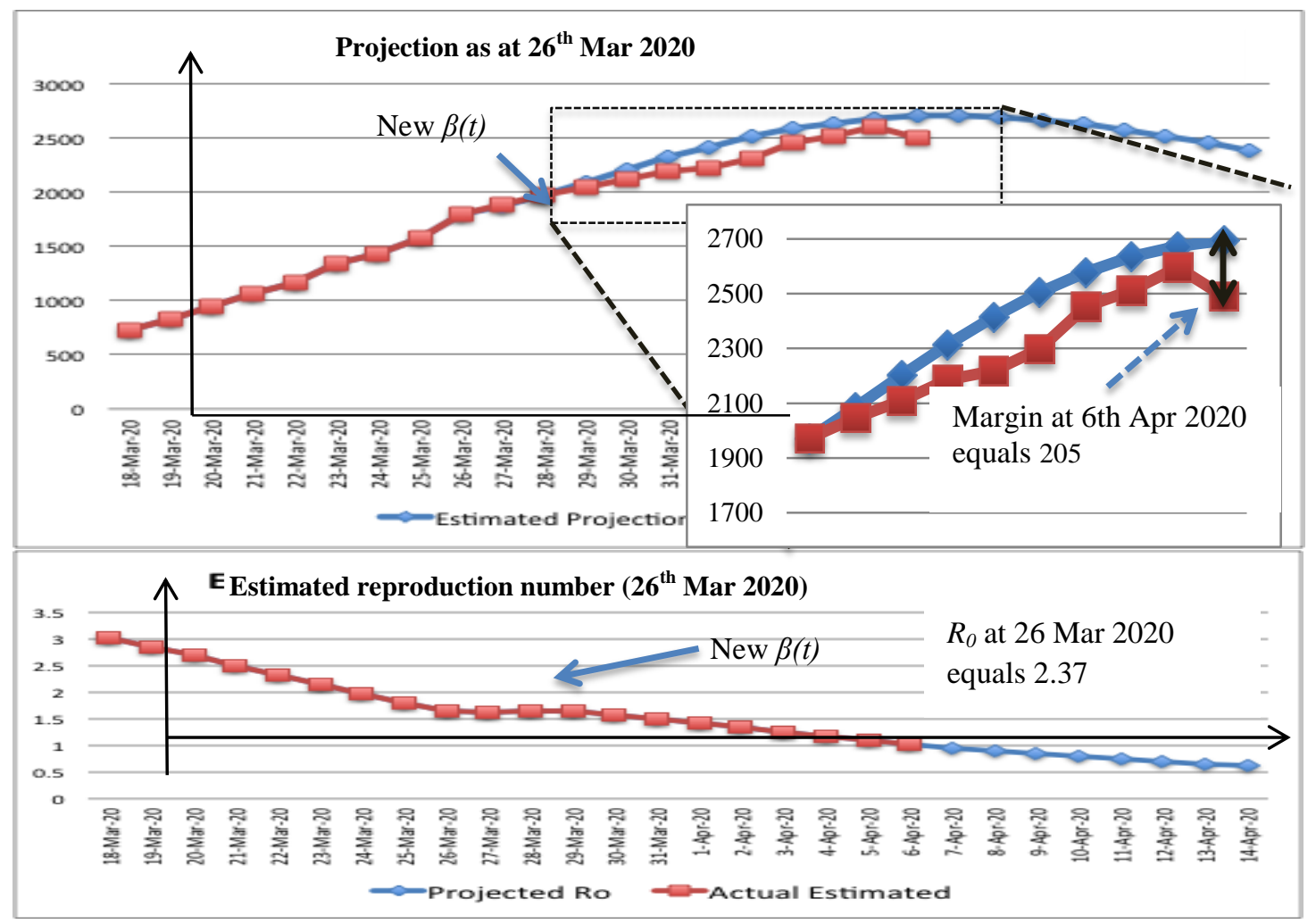

Figure 5 Second projection on 26th Mar 2020

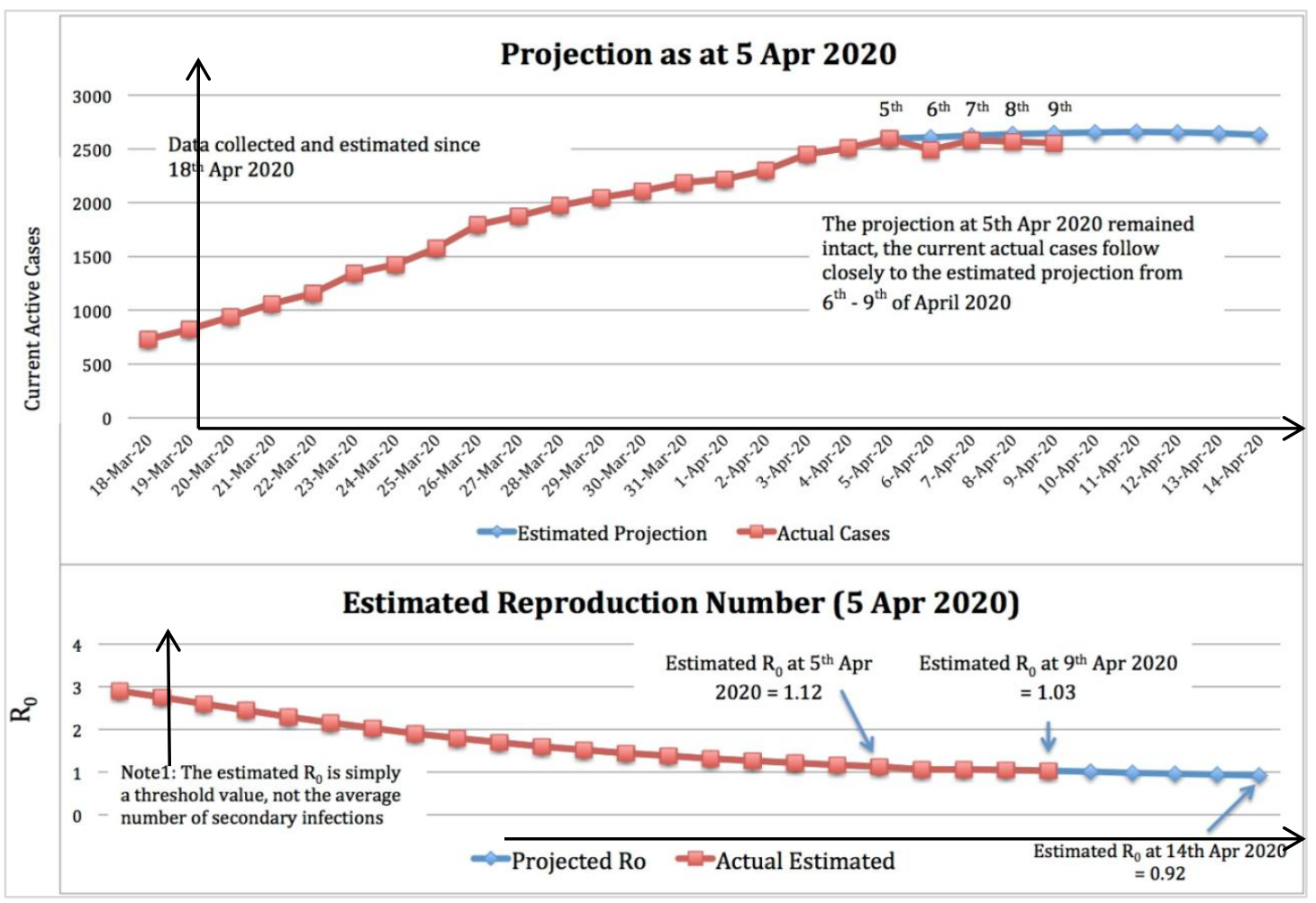

Figure 6 Third projection at 5th Apr 2020

142 


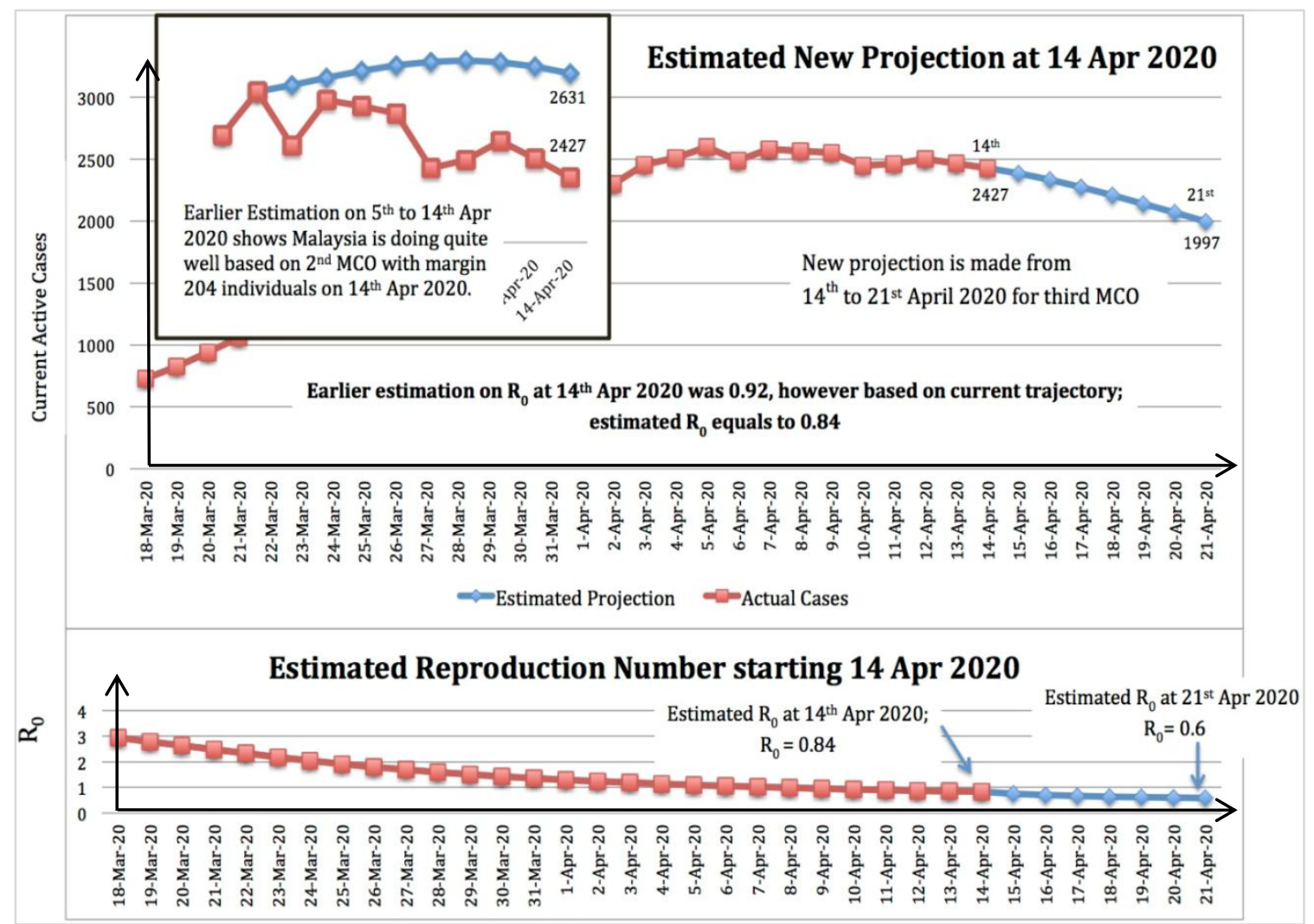

Figure 7 Fourth projection at 14th Apr 2020 under third MCO

Table 2 shows the fitting parameters for closed monitoring projection during the $1^{\text {st }}$ and $2^{\text {nd }}$ MCO. The SEIR parameters were set fixed, that obtained from China trend trajectory (referring to Table 1). Note that the $\xi_{r}$ for second MCO shows significant higher numbers with approximately between 2.5 to 3.6 times higher than the first MCO. This shows that the early detection strategy under the EMCO carried out by the government have shown a very significant improvement.
Figure 8 shows the fitting results for the period of two months starting $15^{\text {th }}$ Feb 2020 until 14th Feb 2020 under closed monitoring. The date on $15^{\text {th }} \mathrm{Feb}$ 2020 is the date of data available from [10], three days after the WHO announced that the 2019 novel coronavirus name change to COVID-19. The fitting shows successful results for the actual number of active cases and follows closely to the actual number of daily cases.

Table 2 Fitting parameters during MCO

\begin{tabular}{|c|c|c|c|c|c|}
\hline \multirow{2}{*}{\multicolumn{2}{|c|}{$\begin{array}{l}\text { SEIR Parameters (fixed) } \\
\text { Dates of } \\
\text { Projection }\end{array}$}} & \multicolumn{4}{|c|}{$\boldsymbol{\rho}=0.00279 ; \hat{\sigma}=0.48555 ; \hat{\gamma}=0.24486$} \\
\hline & & $\alpha$ & $\boldsymbol{k}$ & $\theta$ & $\xi_{r}$ \\
\hline \multirow{2}{*}{$\begin{array}{l}1^{\text {st }} \text { MCO: } 18^{\text {th }}- \\
31^{\text {st }} \operatorname{Mar} 2020\end{array}$} & $22^{\text {nd }}$ Mar 2020 & 0.42632 & 0.000001 & 0.28654 & 3.49 \\
\hline & $26^{\text {th }}$ Mar 2020 & 0.43036 & $6.4911 \mathrm{E}-06$ & 0.26247 & 3.81 \\
\hline \multirow{2}{*}{$\begin{array}{l}2^{\text {nd }} \mathrm{MCO} \\
1^{\text {st }}-14^{\text {th }} \text { Apr } \\
2020\end{array}$} & $05^{\text {th }}$ Apr 2020 & 0.41808 & 0.002376 & 0.08848 & 11.30 \\
\hline & $14^{\text {th }}$ Apr 2020 & 0.42232 & 0.00211 & 0.10074 & 9.93 \\
\hline
\end{tabular}


Ramizi Mohamed et al.

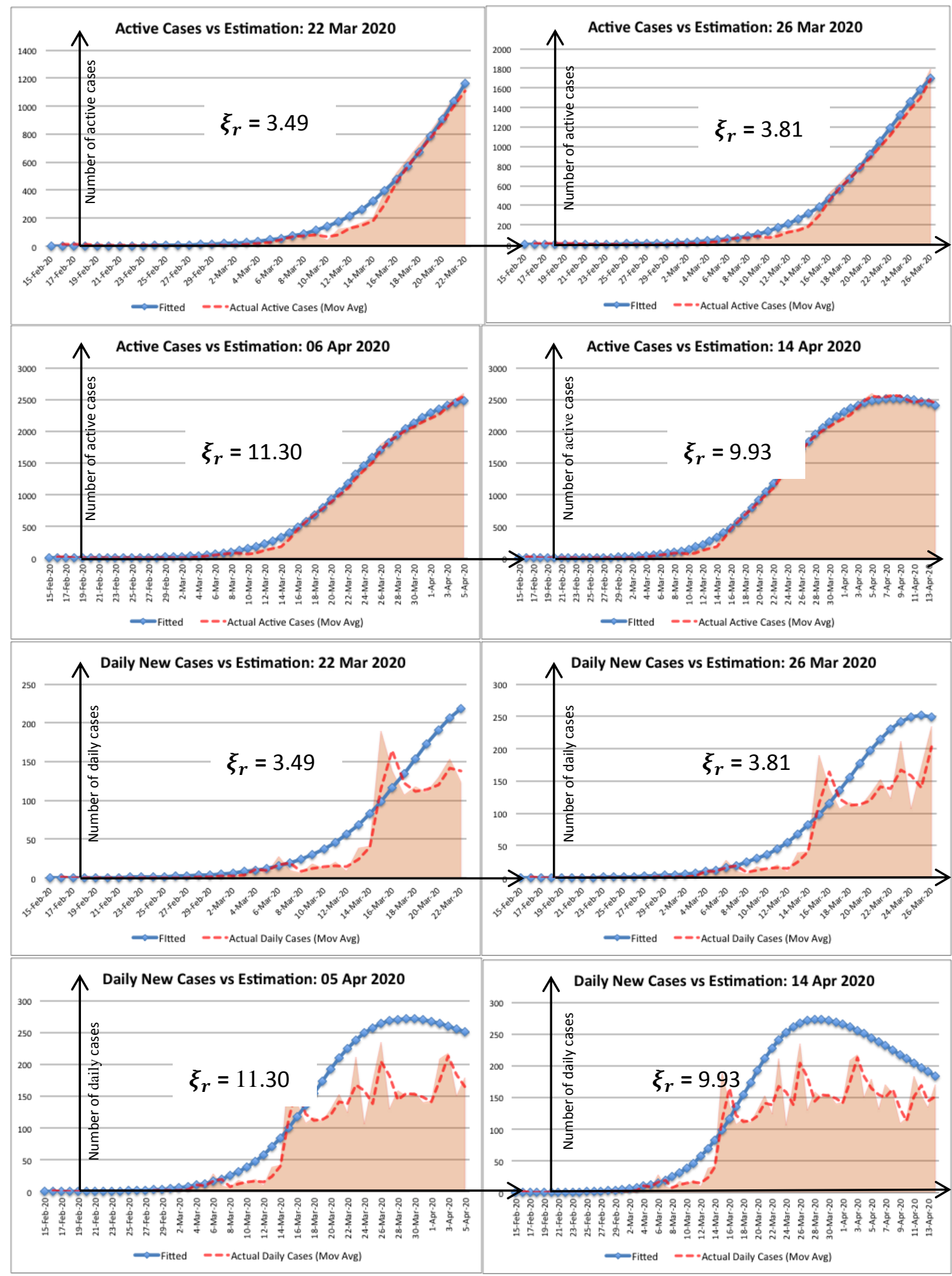

Figure 8 Fitting results with active cases and daily infected cases for the selected consecutive dates and its corresponding early test indicator 
Figure 9 shows the probable full trajectory of COVID-19 until end of Jun 2020, updated on $20^{\text {th }}$ Apr 2020, and Malaysia is currently following the best trajectory.

The full projection is based on several assumptions:

- The trajectory is based on the best and worst possible gradient at the peak number of active cases.

- The actual trajectory may or may not follow the best or the worst case. It depends on the current situation and assessments.
- The lines trajectory would be possible under the current control MCO and positive public response and reaction towards the order.

- The trajectory may be disrupted if at any time the MCO is loosening or retracted.

As listed in the items above, the limitation of the estimation and projection is clearly for higher number of days in estimation. The projection was unable to predict closely for more than two weeks. It is therefore consecutive and closed monitoring for few days would be able to estimate the projection quite accurately.

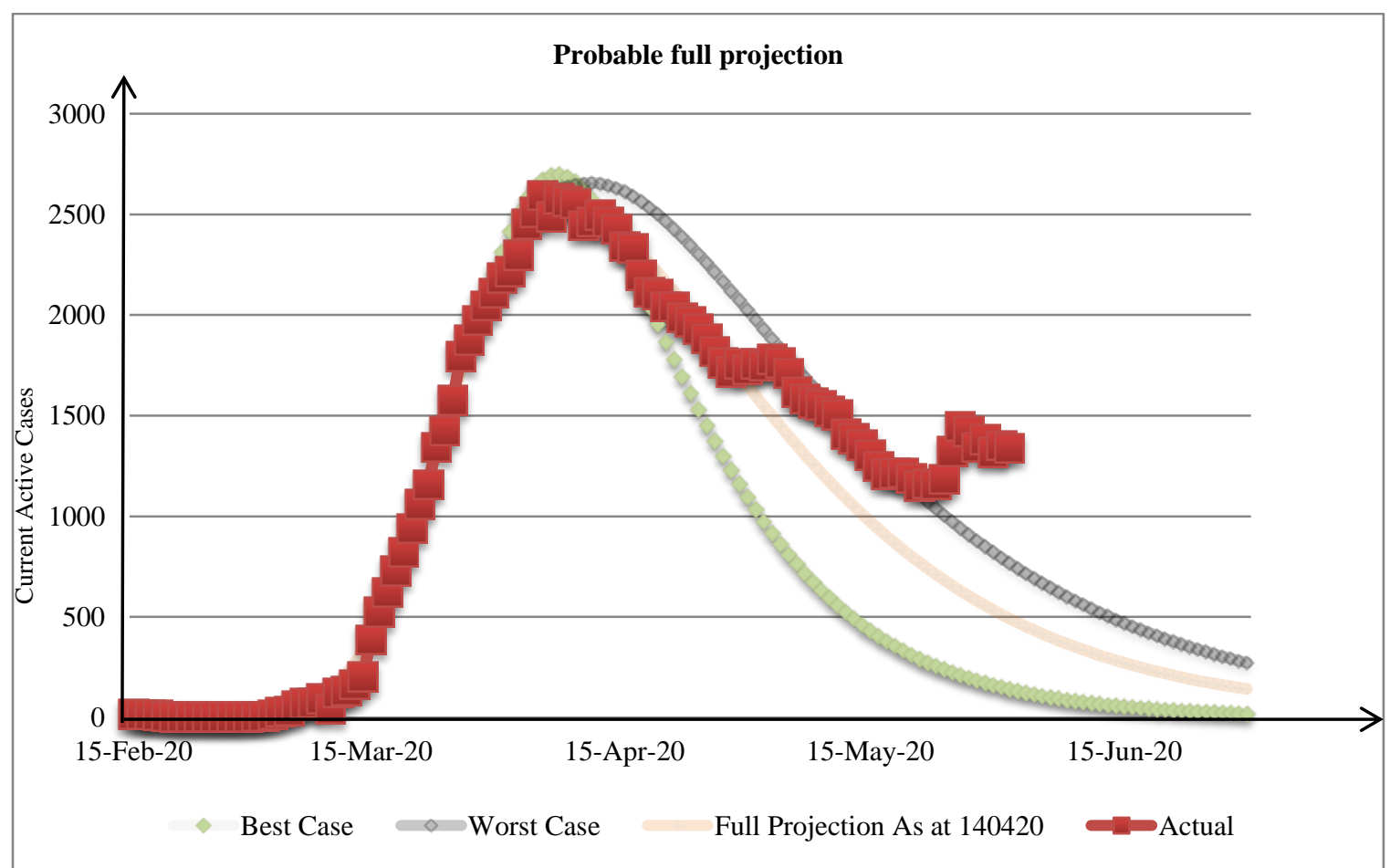

Figure 9 Probable full projection with current trend trajectory, updated $01^{\text {st }} \mathrm{Jun} 2020$

\section{Conclusion}

This paper presents a closed monitoring of Malaysian COVID-19 using a modified SEIR compartmental model for first wave trajectory. The modified SEIR model has shown the capability in assisting and closed monitor the Malaysia COVID-19 trajectory, which proven in agreement to the Malaysian government MCO strategy. The model also suggested three parameter indicators, the enforcement strategy under MCO by the Malaysian government, the early detection strategy for COVID-19 of infected people and positive response and reaction from the public. This is in line with result taken and monitored for Malaysia COVID-19 trajectory. The implementation of MCO by the Malaysian Government has proven to be effective in reducing the $\mathrm{R} 0$ consequently the number of active cases. The second MCO or EMCO is proven to be more effective than the first, which incorporates active screening detection for earlier isolation and treatment, which can be shown by the indicator parameter $\xi_{-} r$ higher under the EMCO. All these of course will not be succeeded if the government received poor response from the public, which will jeopardize the positive trend current trajectory. In conclusion, the strategies proven to be effective and in agreement to the suggested modified SEIR model presented. The future work of the model would be to incorporate the model with secondary infection for longer prediction projection. A 
secondary infection is people who have already recovered and get infected again for second time. This in turn will have a higher chance to estimate the projection number more closely.

\section{Acknowledgment}

The authors would like to thank the Faculty of Engineering and Built Environment, Universiti Kebangsaan Malaysia (UKM), Faculty of Medicine, Universiti Kebangsaan Malaysia (UKM) and the Ministry of Higher Education for the operational and financial support of this project under Project Code COVID-2020-007.

\section{Conflicts of interest}

The authors have no conflicts of interest to declare.

\section{References}

[1] Worldometer China. https://www.worldometers.info/coronavirus/country/c hina/. Accessed 19 October 2020.

[2] Leung K, Wu JT, Liu D, Leung GM. First-wave COVID-19 transmissibility and severity in China outside Hubei after control measures, and secondwave scenario planning: a modelling impact assessment. The Lancet. 2020; 395(10233):1382-93.

[3] https://edition.cnn.com/2020/04/07/asia/coronaviruswuhan-lockdown-lifted-intl-hnk/index.html. Accessed 19 October 2020.

[4] https://www.nytimes.com/2020/04/07/world/asia/wuh an-coronavirus.html. Accessed 19 October 2020.

[5] Times F. Coronavirus tracked: the latest figures as the pandemic spreads. Financial Times. 2020.

[6] https://www.worldometers.info/coronavirus/country/s outh-korea/. Accessed 19 October 2020.

[7] Aylward B, Liang W. Report of the WHO-China joint mission on coronavirus disease. 2019.

[8] Weiss P, Murdoch DR. Clinical course and mortality risk of severe COVID-19. The Lancet. 2020; 395(10229):1014-5.

[9] Vincent JL, Taccone FS. Understanding pathways to death in patients with COVID-19. The Lancet Respiratory Medicine. 2020; 8(5):430-2.

[10] https://www.worldometers.info/coronavirus/coronavir us-cases/. Accessed 15 April 2020.

[11] https://edition.cnn.com/2020/03/20/health/covid-19recovery-rates-intl/index.html. Accessed 15 April 2020.

[12] Liu Y, Yan LM, Wan L, Xiang TX, Le A, Liu JM, et al. Viral dynamics in mild and severe cases of COVID-19. The Lancet Infectious Diseases. 2020; 20(6):656-7.

[13] Chen YC, Lu PE, Chang CS, Liu TH. A timedependent SIR model for COVID-19 with undetectable infected persons. IEEE Transactions on Network Science and Engineering. 2020; 7(4):327994.

[14] Peng L, Yang W, Zhang D, Zhuge C, Hong L. Epidemic analysis of COVID-19 in China by dynamical modeling. arXiv preprint arXiv:2002.06563. 2020.

[15] Prem K, Liu Y, Russell TW, Kucharski AJ, Eggo RM, Davies $\mathrm{N}$, et al. The effect of control strategies to reduce social mixing on outcomes of the COVID-19 epidemic in Wuhan, China: a modelling study. The Lancet Public Health. 2020; 5(5): 261-70.

[16] Yang Z, Zeng Z, Wang K, Wong SS, Liang W, Zanin $M$, et al. Modified SEIR and AI prediction of the epidemics trend of COVID-19 in China under public health interventions. Journal of Thoracic Disease. 2020; 12(3):165-74

[17] Pandey G, Chaudhary P, Gupta R, Pal S. SEIR and regression model based COVID-19 outbreak predictions in India. arXiv preprint arXiv:2004.00958. 2020.

[18] López L, Rodo X. A modified SEIR model to predict the COVID-19 outbreak in Spain and Italy: simulating control scenarios and multi-scale epidemics. SSRN. 2020.

[19] Syafruddin S, Noorani MS. SEIR model for transmission of dengue fever in Selangor Malaysia. In international journal of modern physics: conference series 2012 (pp. 380-9).

[20] Syafruddin S, Noorani MS. SEIR model for transmission of dengue fever. International Journal on Advanced Science Engineering Information Technology. 2012; 2(5):341-5.

[21] Syafruddin S, Noorani MS. Lyapunov function of SIR and SEIR model for transmission of dengue fever disease. International Journal of Simulation and Process Modelling. 2013; 8(2-3):177-84.

[22] https://www.who.int/news-room/detail/23-01-2020statement-on-the-meeting-of-the-international-healthregulations-(2005)-emergency-committee-regardingthe-outbreak-of-novel-coronavirus-(2019-ncov). Accessed 16 April 2020.

[23] Zhao S, Lin Q, Ran J, Musa SS, Yang G, Wang W, et al. Preliminary estimation of the basic reproduction number of novel coronavirus $(2019-\mathrm{nCoV})$ in China, from 2019 to 2020: a data-driven analysis in the early phase of the outbreak. International Journal of Infectious Diseases. 2020; 92:214-7.

[24] Read JM, Bridgen JR, Cummings DA, Ho A, Jewell CP. Novel coronavirus 2019-nCoV: early estimation of epidemiological parameters and epidemic predictions. MedRxiv. 2020.

[25] Majumder M, Mandl KD. Early transmissibility assessment of a novel coronavirus in Wuhan, China. SSRN. 2020.

[26] Imai N, Cori A, Dorigatti I, Baguelin M, Donnelly CA, Riley S, et al. Report 3: transmissibility of 2019nCoV. Imperial College London. 2020.

[27] https://www.csis.org/programs/southeast-asiaprogram/southeast-asia-covid-19-tracker-0. Accessed 14 April 2020.

[28] https://www.mkn.gov.my/web/ms/covid-19/. Accessed 19 October 2020.

[29] http://www.moh.gov.my/index.php/pages/view/2019ncov-wuhan. Accessed 19 October 2020. 
[30] Dos Santos Benedito A, Dos Santos FL. A novel technique to estimate biological parameters in an epidemiology problem. In international workconference on artificial neural networks 2017 (pp. 112-22). Springer, Cham.

[31] http://people.duke.edu/ hpgavin/ce281/lm.pdf. Accessed 13 November 2020.

[32] Mohamed R, Markovsky I, Lewin PL. Modeling and parameter estimation of high voltage transformer using rational transfer function state space approach. In annual report conference on electrical insulation and dielectric phenomena 2008 (pp. 467-70). IEEE.

[33] Mohamed R, Lewin PL. Frequency domain modeling of high voltage transformers using a nonlinear leastsquare estimation technique. In international symposium on high voltage engineering 2009 (pp. 297-302).

[34] He D, Dushoff J, Day T, Ma J, Earn DJ. Inferring the causes of the three waves of the 1918 influenza pandemic in England and Wales. Proceedings of the Royal Society B: Biological Sciences. 2013; 280(1766):1-7.

[35] Qianying L. A conceptual model for the coronavirus disease 2019 (COVID-19) outbreak in Wuhan, China with individual reaction and governmental action. International Journal of Infectious Disease. 2020; 93:211-6.

[36] Lauer SA, Grantz KH, Bi Q, Jones FK, Zheng Q, Meredith HR, et al. The incubation period of coronavirus disease 2019 (COVID-19) from publicly reported confirmed cases: estimation and application. Annals of Internal Medicine. 2020; 172(9):577-82.

[37] Considerations for quarantine of individuals in the context of containment for coronavirus disease Guidance. World Health Organization. 2020.

[38] Zhang J, Litvinova M, Wang W, Wang Y, Deng X, Chen $X$, et al. Evolving epidemiology and transmission dynamics of coronavirus disease 2019 outside Hubei province, China: a descriptive and modelling study. The Lancet Infectious Diseases. 2020; 20(7):793-802.

[39] Wu JT, Leung K, Leung GM. Nowcasting and forecasting the potential domestic and international spread of the 2019-nCoV outbreak originating in Wuhan, China: a modelling study. The Lancet. 2020; 395(10225):689-97.

[40] Anastassopoulou C, Russo L, Tsakris A, Siettos C. Data-based analysis, modelling and forecasting of the COVID-19 outbreak. PloS One. 2020; 15(3):1-21.

[41] Kratz P, Pardoux E, Kepgnou BS. Numerical methods in the context of compartmental models in epidemiology. ESAIM: Proceedings and Surveys. 2015; 48:169-89.
[42] Riou J, Althaus CL. Pattern of early human-to-human transmission of Wuhan 2019 novel coronavirus (2019nCoV), december 2019 to january 2020. Eurosurveillance. 2020; 25(4):1-5.

[43] https://www.theguardian.com/world/2020/feb/13/huge -rise-coronavirus-cases-raises-doubts-scale-epidemicchina. Accessed 19 October 2020.

[44] https://www.bbc.com/news/world-asia-china51482994. Accessed 13 February 2020.

[45] https://www.channelnewsasia.com/news/asia/wuhanvirus-hubei-new-cases-covid-19-coronavirus-newmethod-12429726. Accessed 13 February 2020.

[46] https://www.nst.com.my/news/nation/2020/04/583127 /sri-petaling-tabligh-gathering-remains-msias-largestcovid-19-cluster. Accessed 16 April 2020.

[47] https://en.wikipedia.org/wiki/2020_Malaysia_moveme nt_control_order. Accessed 16 April 2020.

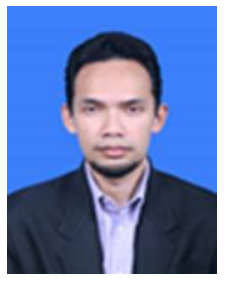

Ramizi Mohamed, is an Associate Professor in the Department of Electrical, Electronic and Systems Engineering, Faculty of Engineering and Built Environment, Universiti Kebangsaan Malaysia. He holds a Bachelor of Engineering from the renowned University of Salford, Manchester, received his Master of Science from Universiti Kebangsaan Malaysia and later graduated from Southampton University with a $\mathrm{PhD}$. In his years lecturing experiences, he specializes in Power Engineering, Instrumentation and Energy Harvesting. Some of his main research interests are Transformer Condition Monitoring, Solar Hybrid Energy Harvesting and Piezoelectric Energy Harvester.

Email: ramizi@ukm.edu.my

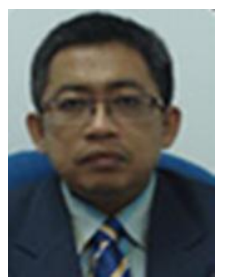

Zulkifli Mohd Nopiah was born in Malaysia in 6 of June 1968. He obtained Bachelor of Science in Mathematics (1991) from University of Minnesota, USA, Master in Science in Operational Research (1995) from University of Southampthon, UK and Ph.D in Portfolio Optimisation (1998) from University of Portsmouth, UK. He is currently the Vice President of Management Science and Operational Research Society Malaysia (MSORSM). He possess a Certtifed Risk Management (CRM) professional certificate. $\mathrm{He}$ has published numerous indexed papers on risk management, waste management and engineering education. Currently, he is the Head of Engineering Education Department at the faculty of Engineering and Built Environment, University Kebangsaan Malaysia, UKM.

Email: zmn@ukm.edu.my 


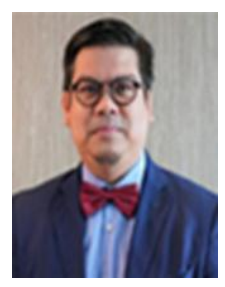

Raja Affendi Raja Ali graduated from National University of Ireland (NUI), with honours degree in medicine in 2000 (M.B., B.Ch., B.A.O.), and completed internship, senior house officer and registrar based training at the University Hospital Galway, Ireland and its affiliated teaching hospitals. $\mathrm{He}$ received Membership of Royal Colleges of Ireland and Edinburgh in 2004 and Masters in Medical Science (M Med.Sc) from NUI in 2005. From 2005 to 2010, he underwent a higher medical training as in gastroenterology, hepatology and internal medicine at the various teaching hospitals in Ireland, receiving certificate of completion of specialist training (CCST) by the RCP Ireland. He also completed a higher diploma in clinical teaching at the NUI as well as conferred a doctorate of Medicine, MD degree for his research on relationship between inflammatory bowel disease and colorectal cancer at the department of Clinical Pharmacology and Therapeutics and Regenerative Medicine, NUI. He then undertook a consultant physician and gastroenterologist at the University Hospital Galway before returning to The National University of Malaysia Medical Centre, Kuala Lumpur to take up a consultant physician and gastroenterologist and associate professor in Medicine. He has been awarded several research grants by the Ministry of Higher Education, Malaysia, professional societies and industries. His research and clinical interest focuses on inflammatory bowel disease, irritable bowel syndrome, colorectal cancer and gut microbiome. He is a fellow of the Royal College of Physicians of Edinburgh (FRCP, Edin), UK and American Gastroenterological Association (AGAF). He currently serves as a Dean and Professor of Medicine at The National University of Malaysia Medical Centre, Kuala Lumpur, Malaysia.

Email: draffendi@ppukm.ukm.edu.my 